\title{
Integrated Automatic Power Factor for 3-Phase Load and Management in Home Appliances using IoT
}

\author{
B. Rajesh Kumar, S. Ishwarya, R. Senthil Kumar
}

\begin{abstract}
In this project, importance of Energy audit, management and control are put forth as need for future power crisis. A sincere attempt has been made to conduct energy audit in every electrical home appliance using the advanced technology of Internet of Things. In this system proper energy management algorithm as well as power factor correction is also used to reduce the overall monthly average power consumption in a home. Also, detailed analysis of data collected is done by suggesting cost-effective measures to improve the energy efficiency of use. Estimation of implementation costs and payback periods for each recommended action has been made. The result \& vital information generated through these activities are documented. The Energy Auditing for a day is the index of the consumption which normalize the situation of Energy crises by providing the conservation schemes.
\end{abstract} grid.

Keywords: Arduino Uno, Capacitor bank, Power factor, Smart

\section{INTRODUCTION}

In any organization, expenses on operation are depends on the three major components like energy (both heat and electrical), workman and raw materials. If one could like to save cost or potential cost among the above components, emphasis on energy rather than other because that could save more on principal amount and thus energy management is the place for save more cost.

The way of Electrical Energy Consumption can be understood with the help of energy audit, Management and control process. Moreover, the way in which energy can be wasted and where scope for improvement exists. Energy production cost, Preventive maintenance and quality approaches by the energy management system play an important role for power generation and utility activities. Such a Energy management system will focus on variation in the cost, resources availability and reliability to the consumer, took decision for hybrid energy, alternate technologies for energy conservation etc. In general, Energy management system is the translation of conservation ideas into realities, by lending technically feasible solutions with economic and other organizational considerations within a specified time frame [1]. The fundamental objective of Energy management

Revised Manuscript Received on November 15, 2019

* Correspondence Author

B. Rajesh Kumar *, Department of Electronics and Communication Engineering, M. Kumarasamy College of Engineering, Karur, India S. Ishwarya, Department of Electrical and Electronics Engineering, M. Kumarasamy College of Engineering, Karur, India

R. Senthil Kumar, Department of Electrical and Electronics Engineering, Sri Krishna College of Technology, Coimbatore, India. is to supply quality power with least environmental issues. Energy auditing is the fundamental approach for making decision in the energy management. The recent technology has to be implemented to control and monitor power consumption in the consumer premises. Internet of Things provides the easy control of power flow to every electrical equipment and energy can be managed by programming in the Arduino Uno [2-4]. The main objective by this work is to monitor and control the energy consumption by every electrical equipment as well control the power factor correction, so as to improve the quality of power and energy.In conventional electricity management system, normal energy meter calculated the load power for certain period of time as energy consumption [5]. Moreover, no control equipment is available to monitor the energy consumption by the load. In this proposed system a novel approach has been made through the recent technology called Internet of Things technology provides the solution for the conventional problems [6]. In this approach IoT technology is used to program that electrical equipment are supplied with power only under required situation and also if the equipment is consuming more lagging power is supplied with alternative capacitor bank to make it as leading power in order to maintain power factor as unity [7]. It also provides to manage the power capability for every month by fixing the threshold point for every equipment power consumption. Power crisis increases day by day, so IoT provide the better solution for avoiding waste power management. Energy Management are often used by individual entities to monitor, control and measure in their electrical building equipment. This system can act as centrally controlled equipment to control individual appliances or control overall system. Data obtained by this approach can be used for self diagnostic as well finding the optimized solution for the system.Energymanagement software was developed for continuous tracking of utility billing system[9].In order to reduce the cost of power generation by the generating station, the power factor of the circuit must be mounted as unity.Practically,no power factor is maintained as unity because of inductive loads and some Non-Linear Loads, so capacitor banks can be used for maintain power factor as unity under lagging.

\section{METHODOLOGY}

In order to move our system in efficient way, the methodology adopted for energy auditing must be formulated properly. It might differ from one organization to other, however, the objective of energy auditing and monitoring must be fulfilled whatever the methodology adopted, so as to auditor aware about the activities during auditing phase.

The following are the methodologies required for energy management in consumer premises:

A. Required Data Collection 
In consumer premises(or) home automation system, the required data collection is nothing but, identifying the various available loads in a particular room. The specification for each load and required time to be run are formulated. For instance, two loads to be consider like one Air conditioner and a fan, the total energy consumed by these loads are calculated. This is the primary and necessary step to be carried out first called data collection.

\section{B. Analysis of Data}

Data analysis can be done by using particular and suitable analytical formulas to calculate required energy for a particular month. Average energy consumption can be monitor, control and maintain for cost saving. Daily usage of energy can be altered and fixed to maintain total average energy consumption.

\section{Fixing of recommended methodology}

Based on the previous steps and result analysis, the new methodology to be fixed which will not affect the existing system performance rather it will improve and progressively saving should arise

\section{Power Factor Correction}

The effect of low power factor in electrical utility has been discussed for so many years and incentives for corrective action in the consumer side increases, although it causes handicap to better and efficient electricity services. Primarily the power factor correction offers the better services to the consumer as well as good quality of power to consumer which will further improve the durability of all electrical utility. Power factor improvement will also offer better voltage regulation of the system in turn availability of good quality of power.Secondarily,it can improve the release capacity of the system with less investment results in reduction of losses with less operating charges tunes the existing system will support better quality of power to save electrical utilities.

\section{E. Power Factor}

Power factor of a circuit is basically defining as the cosine of the angle between Voltage and Current. As per the power angle definition, it is the ratio between true power and the apparent power[8]. The power factor triangle is shown in Fig. 1

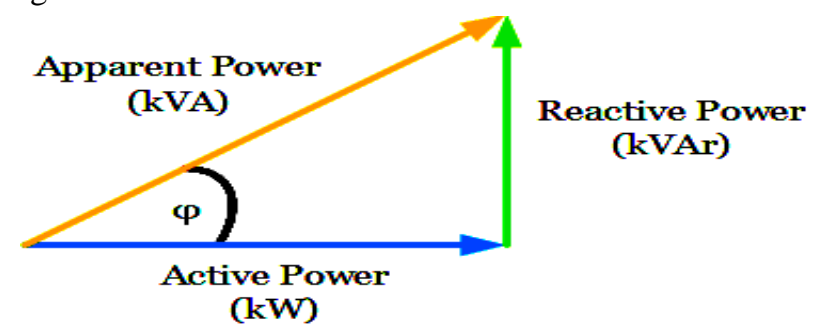

Fig. 1.Power Factor angle

Power Factor will be differ for different load condition.All the electrical equipments will fall under the three categories namely Resistive,Inductive and Capacitive.The figure 1 shows the total power generation in which the actual power available to the load will be real power and the power consumed by the inbetween electrical components called reactive power.

\section{F. Power Factor Under Various Electrical Loads}

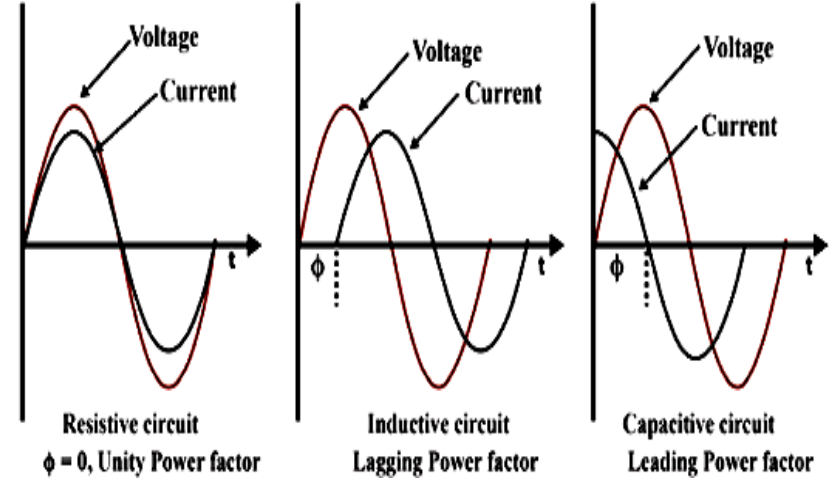

Fig. 2. Power Factor Under Different Loads

Fig. 2 represents the different power factor angle under different load conditions. For purely inductive loads the current lags the voltage by 90 degree. Similarly, for the capacitive load current leads by 90 degree. Under resistive load the current and voltage are in phase with each other[9].

Three major factors to be consider for PFC are,

- Power factor correction location to be decided,

- Type of PFC Equipment going to be used.

- Establishment of PFC must take PF directly or indirectly

\section{HARDWARE IMPLEMENTATION}

\section{A. Existing System}

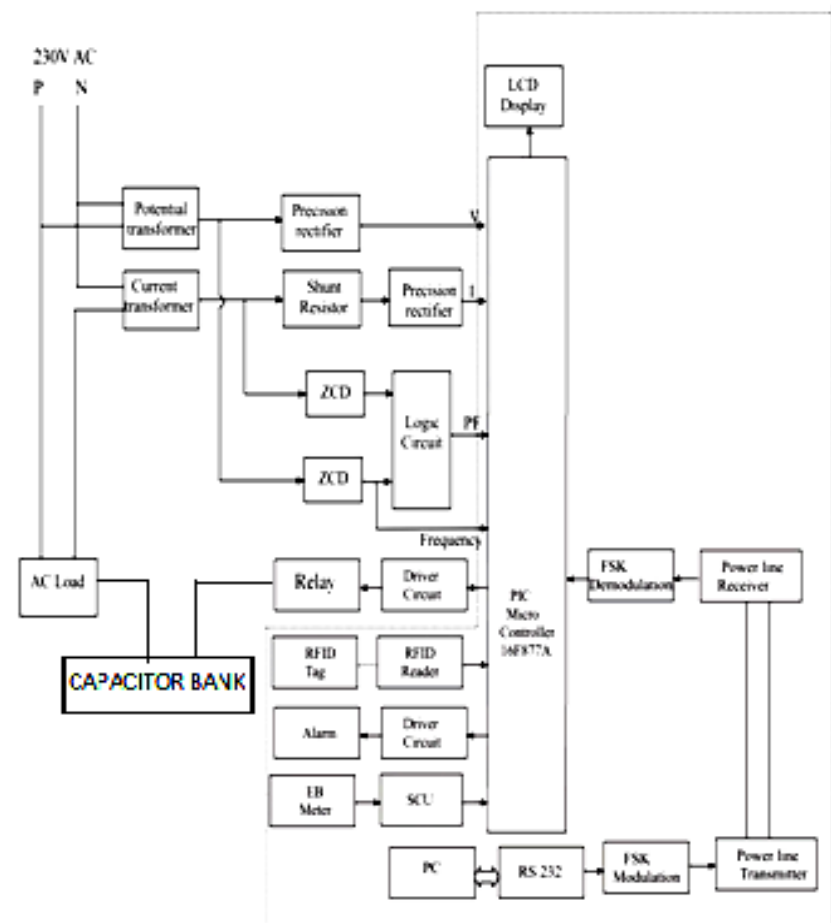

Fig.3 Block diagram of Existing System

Fig. 3 shows the existing system of power factor correction which is based on RFID Technic. In the above system RFID tag is used to recharge as like prepaid electricity charge card. Whenever required energy is utilized it will give intimation through alarming or mobile message using GPS system.PIC controller will call the PFC routine whenever it founds signal from the AC load is more 
inductive. The capacitor bank comes into picture and supply leading Power Factor in order to compensate lagging power[10-12].

Instrument transformers are used to detect the load Voltage and Current and give an input to the PIC controller. The function of Zero crossing detector is used to detect the input signal voltage and current compares with the predefined values so that Controller can took decision accordingly. If the controller senses low power factor ,through driver circuits it automatically connects reactive power compensation capacitor bank to the load circuits.

A smart grid can be rightly defined as a modernized electrical grid which uses the information and communication technology to collate and assimilate ideas and behavior of the suppliers and consumers automatically in order to enhance the efficiency and uniqueness in the production and distribution of electricity[13].

\section{B. Proposed System IoT based EMS}

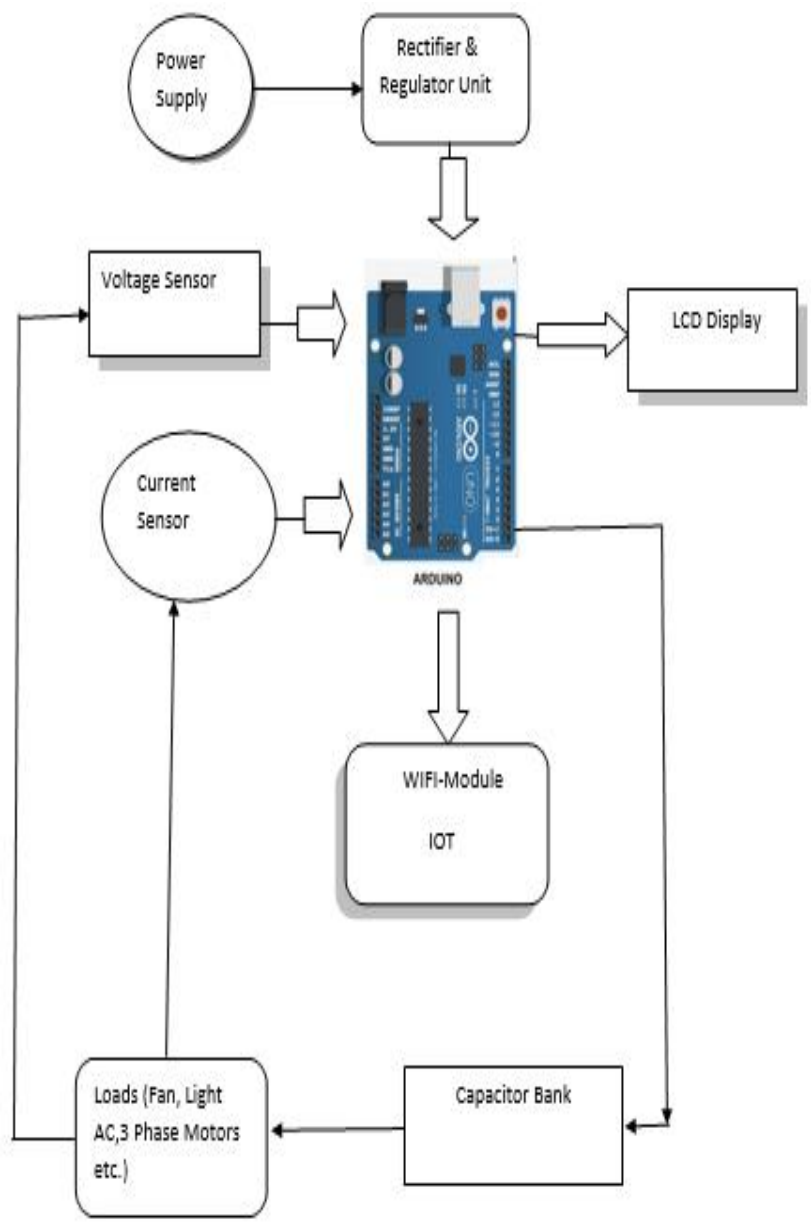

Fig.4 Proposed IoT Model for EMS

The proposed model based on IoT exhibit unique property of control using Arduino Uno board. It has the advanced technology that programming can change the settings whenever it requires. Internet of Things is the evolutionary technology nowadays. It offers ease of monitor, control and maintain the energy saving as well as PFC.In the proposed system, every load is connected with voltage sensor and current sensor which will sense the power consumption. The power supply to loads are already predefined by the programming of Arduino Uno on everyday as well every hour basis based on the climatic condition availability. For example, during cold condition no usage of Air conditioner and fans, instead the power availability can be used for heater alone, this setting can be done in Arduino programming. Accordingly, the daily average setting or monthly average setting for power savings can be made. Moreover, any three-phase load causes low power factor can also compensate by capacitor bank that too controlled by Arduino Uno Programming[14].

\section{Arduino Uno}

Arduino is an electronics platform for easy use as open source to software and hardware. By using Arduino programming language and Arduino IDE Software, can be programmed the microcontroller inside the board. It can get input through sensors and actuate the output in LED or LCD Displays. Ivrea interaction design institute has developed this open source platform for easy design of electronics project without background of electronics and programming knowledge. As its feature of anytime update, the programming can be easily modified for various environments like wearable projects, IoT applications and embedded projects[15]

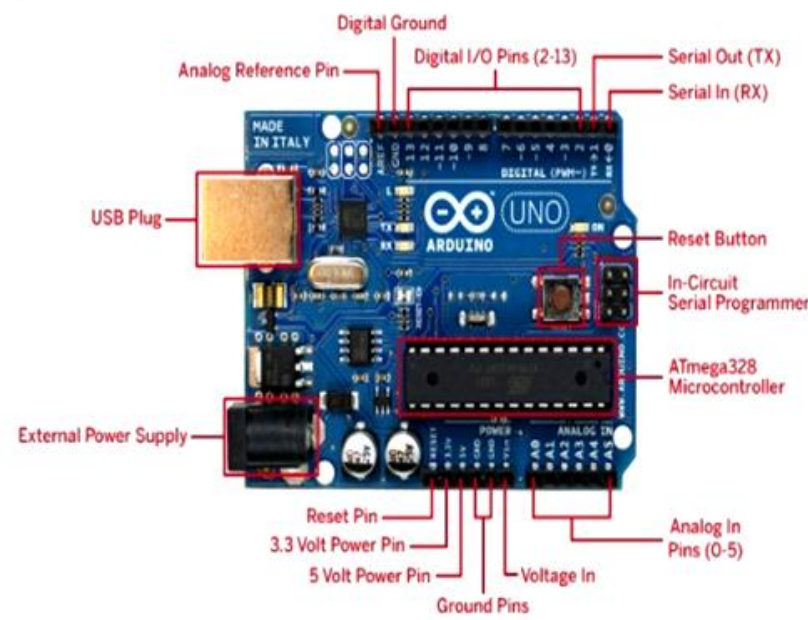

Fig.5 Arduino Uno Board with PIN configurations Features of Arduino Uno:

- It is less expensive one compared with advanced microcontroller unit.

- It works on cross platforms like Macintosh OSX, Windows. Most of the microcontrollers are restricted with Windows alone.

- Arduino Software (IDE) is easy to use for beginners.

- It is an open source and extendable software and hardware tool.

Writing program using Arduino software (IDE) are called as sketches. Text editors are written with sketches and save a file with .ino file extension. Text editors are available with options like pasting/cutting/replacing. IDE tool will display the error message and gives feedback while saving. Bottom righthand corner of the window will display the configured board and serial port. IDE software tool allows to handle more than one file[16].

During uploading, if you are using arduino bootloader, it allows you a small program has been loaded to microcontroller. The bootloader will blink on the LED (Pin 3) when it starts.

\section{Sensors}

Industry and organization have been used various types of sensors

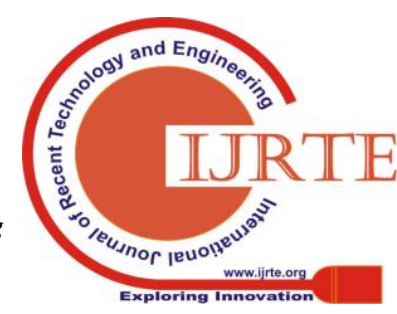


for IoT application projects. IoT intelligent platform will collect data from sensors and push into the network connected devices. By combining a set of sensors and network connected devices, sharing the data among them for better functionality and good reliability. Voltage and current sensors unit which is shown in Fig.6

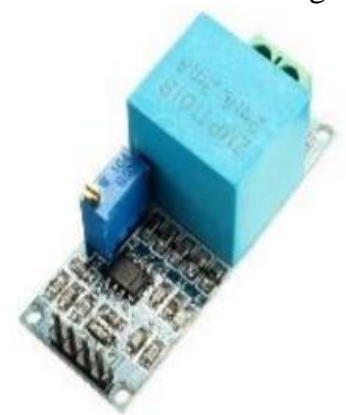

(a)

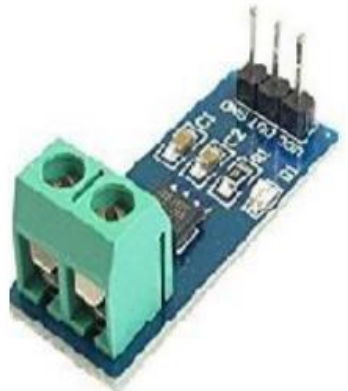

(b)
Fig.6 a) Voltage Sensor Unit b) Current Sensor Unit

The Voltage sensor unit is designed to measure RMS value of single phase as well as three phase voltage based on the application circuit. The current measuring circuit is based on Allegro ACS712 Sensor, able to measure AC or DC current. It is of three types from manufacturer based on the ratings like $\pm 5 \mathrm{~A}, \pm 20 \mathrm{~A}, \pm 30 \mathrm{~A}$.

\section{E. Capacitor Bank}

Capacitive load will offer leading power factor in the power system. Most of the three phase loads are drawn more reactive power from the supply. This in turn increases the active power generation in order to maintain power angle of the circuit. Reactive power compensation is the management of reactive power in AC system.in the proposed system, it's a part of having load compensation along with EMS. The following are the improvements obtained through load compensation[17].

- It improves the power factor of the system.

- Maintain balancing in the real power drawn.

- Voltage Regulation Compensation.

- Elimination of current Harmonics.

Normally residential customers are charged for real power alone because of every nearby residential customer use only real power load. For any industrial applications or any Three phase supply is used by the consumer has to be provided with capacitor bank for reactive power compensation. Generally, for a load with power factor less than 0.95 is consider to be supply with reactive power whereas more than 0.95 is consider as good power factor and maintained at 1.0 is consider as perfect value. representation and do the finalized comparison for power factor. Once the power factor is maintained, capacitor bank is cut down from being supplied reactive power to the inductive load. Flow chart is shown in Fig.7.

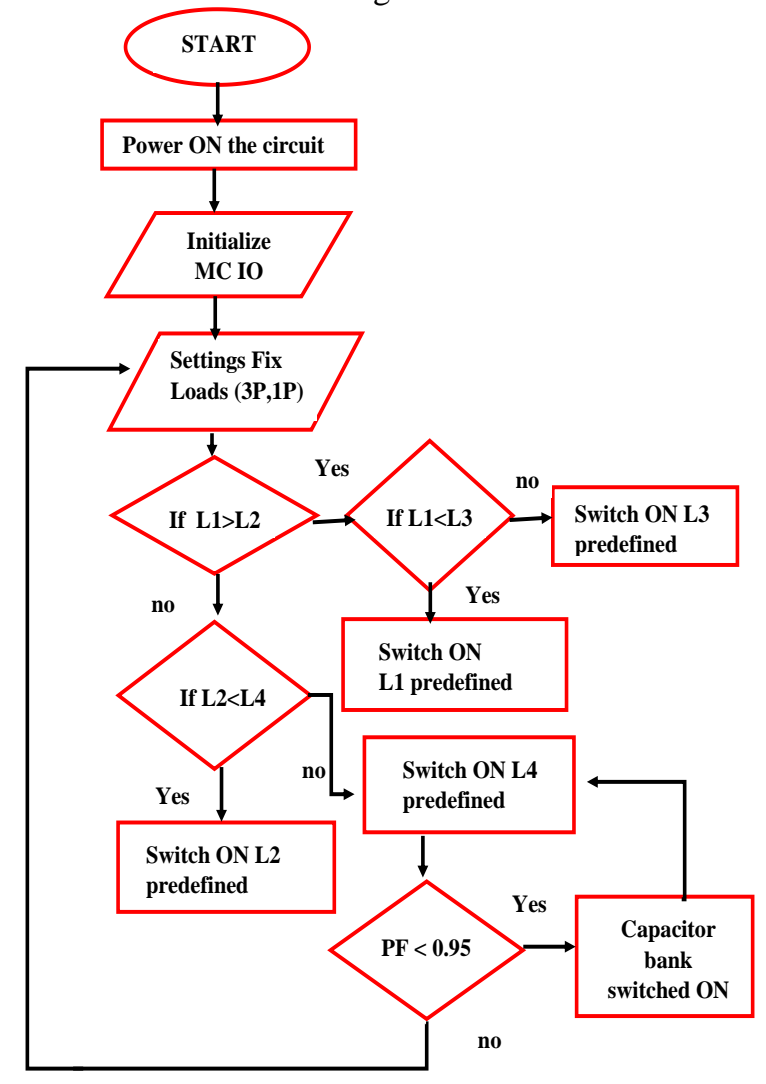

Fig.7.Flow Chart of Proposed System

Fig.8(a) and (b) shows the output results for IoT based energy monitoring and control System. Complete chart has been created among various electrical appliances vs $\mathrm{KWhr}$ and Cost/day.

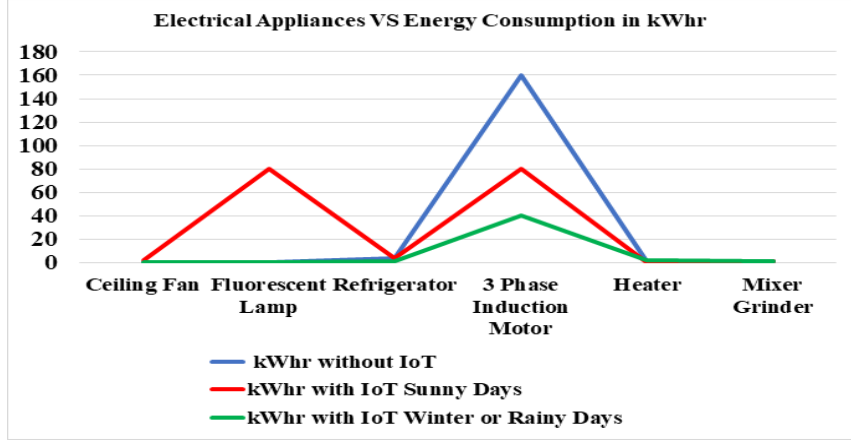

Fig.8 a)Electrical Appliances VS Energy Consumption in KWhr

\section{RESULTS AND DISCUSSION}

\section{A. Flow Chart}

The flowchart represents the overall steps to be happen in this project. Here a novel approach was developed to define the loads. In this both the single phase and three phase loads are consider in a same premise. Arduino IDE software initialize the microcontroller with specific loads.Comparision among the loads are made with while loop 


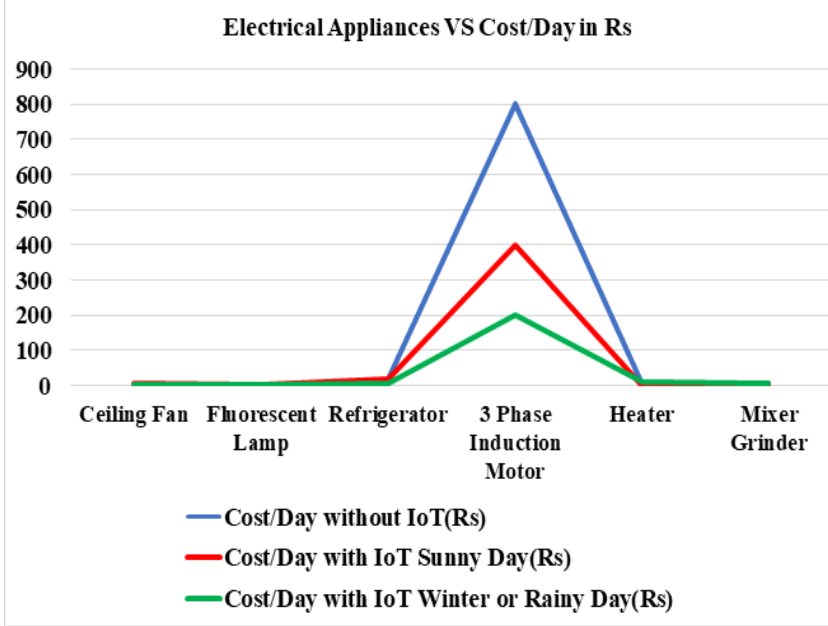

\section{B. Source Code}
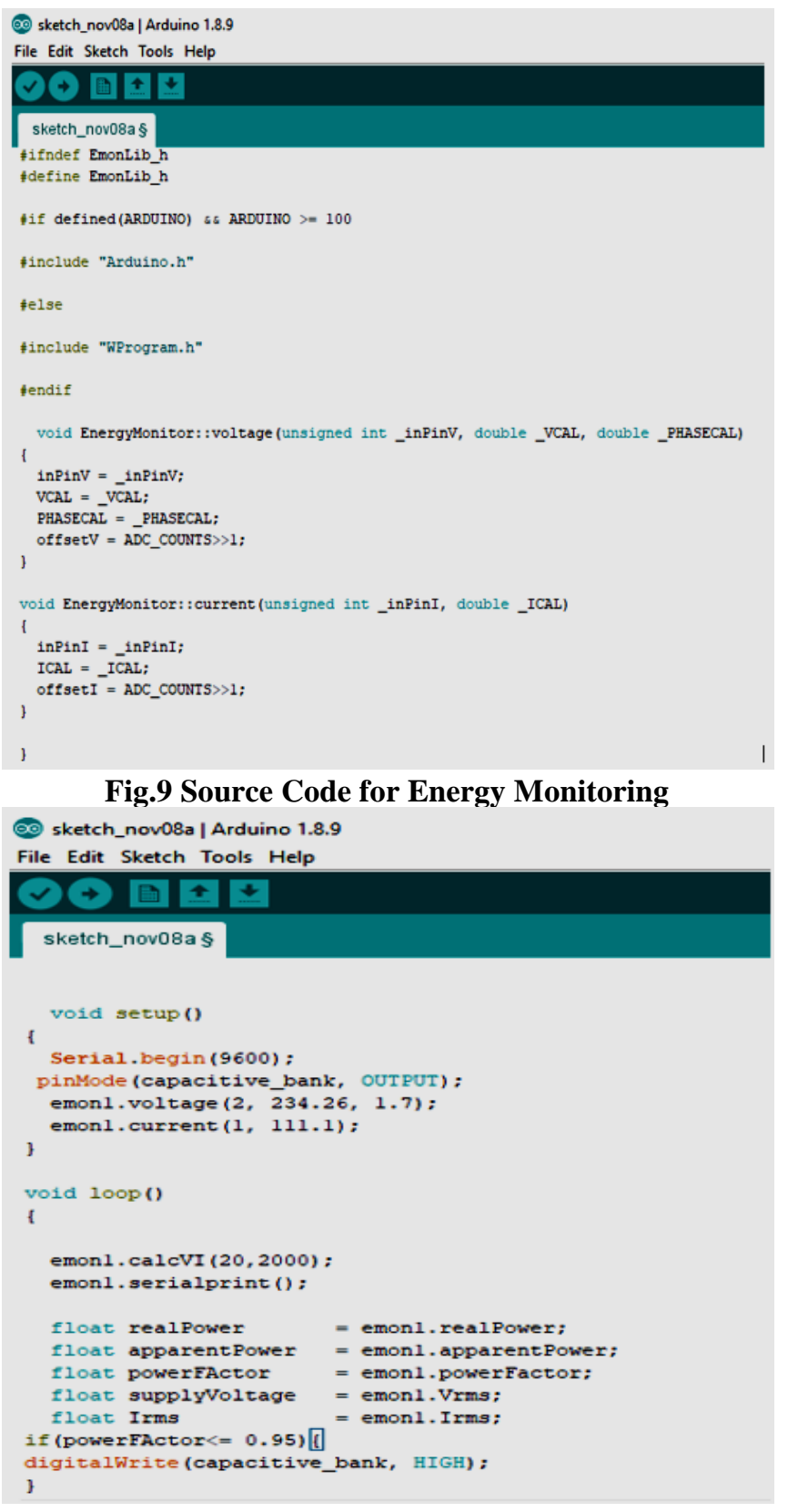

Fig.10 Source Code for Capacitor Bank

\section{Source Code}

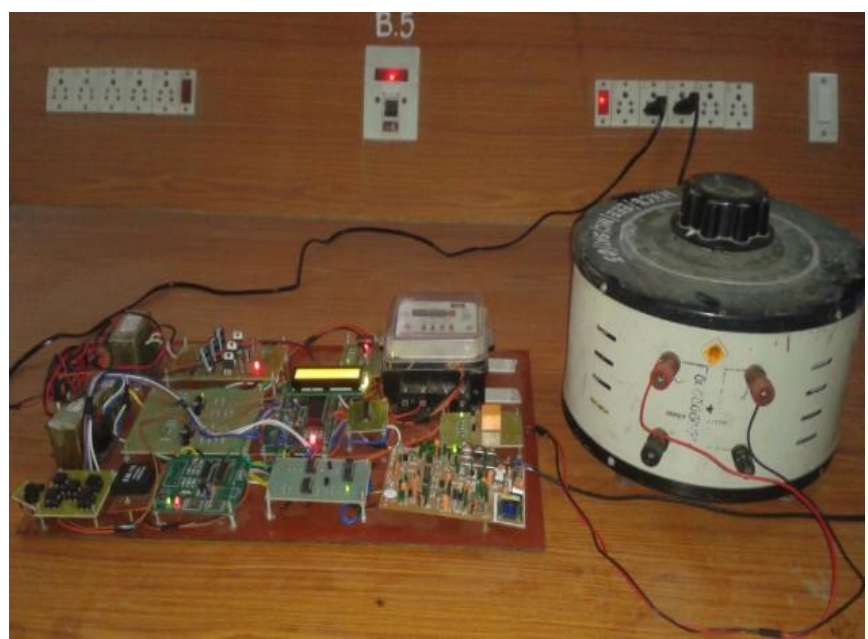

Fig.11 Hardware setup for consumer side

Features of Proposed System

- Daily settings provide the option for monitor and control over energy saving by consumer.

- Involvement of Recent technologies like IoT make the system can be upgradable whenever it requires.

- Cost involved in the overall system is comparably lesser than existing system.

- Remotely connect or disconnect monitoring system helps to control wherever the consumer wants.

- Reactive power compensation using capacitor bank.

\section{CONCLUSION}

Automation and Smart energy management are the dual objectives involved in the recent technologies for providing user friendly power supply to the energy users technology enables the proposed system will save energy on daily basis by settings provided based on the climatic condition, which have a control over cost/day. More over it allows the control in reactive power compensation for maintaining power factor of the system in order to reduce the cost of generation in three phase loads by using capacitor bank

\section{REFERENCES}

1. L W W Morrow, "Power Factor Correction" Journal of the A.I.E.E.44(2),15-156.

2. Leninpugalhanthi, P., et al. "Power Theft Identification System Using Iot." 2019 5th International Conference on Advanced Computing \& Communication Systems (ICACCS). IEEE, 2019.

3. Sarasvathi, K., M. Lincy Luciana, and R. Senthil Kumar. "Comparison of sine, hysteresis, SVPWM and predictive PWM techniques for shunt active power filter." 2017 IEEE International Conference on Electrical, Instrumentation and Communication Engineering (ICEICE). IEEE, 2017.

4. Rajan S P, Sheikdavood K, "Performance Evaluation on Automatic Follicles Detection in the Ovary", International Journal of Applied Engineering Research, ISSN No.: 0973-4562, Vol. 10, Issue 55, pp. $1-5,2015$

5. Fawzi Al-Naima, BahaaJalil "Building a Prototype Prepaid Electricity Metering System Based on RFID” International Journal of electronics and Electrical Engineering ISSN : 2277-7040 Volume 1 Issue 1.

6. Yathrath Gupta,Shiv Prakash Bajoria,Rahul Kumar Singh,Dr.O.V.Gnana Swathika"IoT Based Energy Management System with load sharing and source Management Features", 2017 4th IEEE Uttar Pradesh Section International Conference on Electrical, Computer and Electronics (UPCON) GLA University, Mathura, Oct 26-28, 2017.

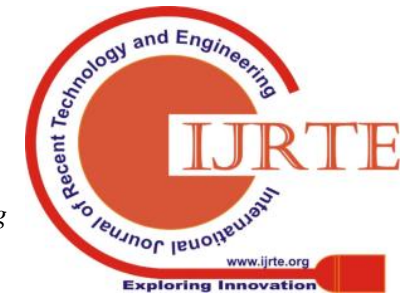


7. S.Palanivel Rajan, "A Significant and Vital Glance on "Stress and Fitness Monitoring Embedded on a Modern Telematics Platform", Telemedicine and e-Health Journal, ISSN: 1530- 5627 (Online ISSN: 1556-3669), Vol. No.: 20, Issue No.: 8, pages: 757-758, 2014.

8. Q.F.Hassan,'Introduction to the Internet of Things,"in Internet of Things A TO z:Technologies and applications,IEEE,2018.

9. Loganathan, G., et al. "An enhanced time effective particle swarm intelligence for the practical economic load dispatch." 2014 IEEE 2nd International Conference on Electrical Energy Systems (ICEES). IEEE, 2014.

10. S.Palanivel Rajan, V.Kavitha, "Diagnosis of Cardiovascular Diseases using Retinal Images through Vessel Segmentation Graph", Current Medical Imaging Reviews (Bentham Science Publisher), Online ISSN No.: 1875-6603, Print ISSN No.: 1573-4056, Vol. No.: 13, Issue : 4, pp. 454-459, (Impact Factor-0.613), 2017.

11. Takanori Washiro "Applications of RFID Over Power Line for Smart Grid” 2012 IEEE International Symposium on Power Line Communications and Its Applications.

12. Prakash Pawar,Panduranga Vittal K,"Design and development of advanced smart energy management system integrated with IoT framework in smart grid environment"Journal of Energy Storage 25(2019)10086.

13. C.Vivek, S.Palanivel Rajan, "Z-TCAM : An Efficient Memory Architecture Based TCAM", Asian Journal of Information Technology, ISSN No.: 1682-3915, Vol. No.: 15, Issue : 3, pp. 448-454, 2016.

14. Vehebi,DilanSachin,Taskinkocak,SalihErgiit,CconcentinaBuccela,Carl oCeloti,GerhardP.Hancke "smart grid Technologies: Communication Technologies and Standards" IEEE transactions on industrial informatics, vol. 7, no. 4, november 2011

15. S.Vijayprasath, S.Palanivel Rajan, "Performance Investigation of an Implicit Instrumentation Tool for Deadened Patients Using Common Eye Developments as a Paradigm”, International Journal of Applied Engineering Research, ISSN No.: 0973-4562, Vol. 10, Issue No.1, pp. 925-929, 2015

16. Gokul, R., et al. "Digitilized water consumption tracking cum awareness system." 2019 5th International Conference on Advanced Computing \& Communication Systems (ICACCS). IEEE, 2019.

17. Maheswar, R., et al. "Energy Efficient Real Time Environmental Monitoring System Using Buffer Management Protocol." 2018 9th International Conference on Computing, Communication and Networking Technologies (ICCCNT). IEEE, 2018.

\section{AUTHORS PROFILE}

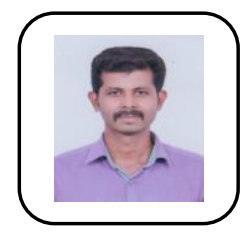

B.Rajesh Kumar received UG degree from V.S.B Engineering College, Karur, Tamil nadu. He got PG degree from Jayaram College of Engineering, Trichy, Tamil nadu. He attended more conferences and presented more reputed papers in the field of Applied Electronics and renewable energy sources. Currently he is working as an Assistant Professor in M.Kumarasamy College of Engineering, Karur. His interest is in the field of Electronics Device, Renewable energy sources and Intelligent Techniques.

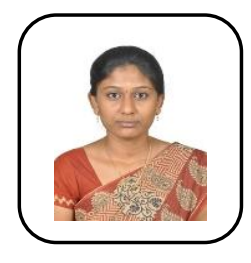

S.Ishwarya received UG degree from M.I.E.T Engineering College, Trichy, Tamil nadu. She received PG degree from M.Kumarasamy college of Engineering, Karur. Tamil nadu. She attended more conferences and presented more reputed papers in the field of Power system and renewable energy sources. Currently she is working as an Assistant Professor in M.Kumarasamy College of Engineering, Karur. Her interest is in the field of Power systems, Control systems and Intelligent Techniques.

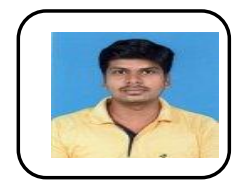

R.Senthil kumar got UG degree from PSNA college of Engineering, Dindigul, Tamil nadu. He got PG degree from the same college. He attended more conferences and presented more reputed papers in the field of Power Electronics and Drives. Currently he is working as an Assistant Professor in Sri Krishna College of Technology, Coimbatore. His interest is in the field of Power electronics control and soft computing techniques.. 